Artigo $\begin{aligned} & \begin{array}{l}\text { Pesquisa Florestal Brasileira } \\ \text { Brazilian Journal of Forestry Research } \\ \text { http://pfb.cnpf.embrapa.br/pfb/ }\end{array} \\ & \text { Ap-ISSN: 1983-2605 }\end{aligned}$

\title{
Efeito de diferentes períodos de cultivo na micropropagação de brotações de Luehea divaricata
}

\author{
Karol Buuron da Silva ${ }^{1}$ (D), Lia Rejane Silveira Reiniger ${ }^{1}$ (D), Silvia Machado dos Santos Rabaiolli ${ }^{1}$ (D), Ana Cristina da Fonseca Ziegler ${ }^{1}$ (D), \\ Charlene Moro Stefanel ${ }^{1}$ id
}

${ }^{1}$ Universidade Federal de Santa Maria, Avenida Roraima, n 1000, CEP 97105-900, Santa Maria, RS, Brasil

"Autor correspondente:

karolbuuron@hotmail.com

Termos para indexação:

Açoita-cavalo

Cultivo in vitro

Senescência

Index terms:

Açoita-cavalo

In vitro culture

Senescence

Histórico do artigo:

Recebido em 26/03/2019

Aprovado em 30/09/2020

Publicado em 31/08/2021
Resumo - O objetivo do presente trabalho foi avaliar o efeito do período de cultivo na micropropagação de brotações de Luehea divaricata. Os tratamentos foram compostos pelos períodos de cultivo in vitro: $14 ; 21 ; 28 ; 40 ; 56 ; 70 ; 84 ; 102 ; 116 ; 130 ; 154,186$ ou 200 dias, sem realizar subcultivo ou transferência para outro meio nutritivo fresco. A sobrevivência e o estabelecimento ficaram em torno de $90 \%$ até 84 dias de cultivo. A partir deste período, a mortalidade foi mais acentuada. Para as variáveis número total de folhas e folhas com senescência, o período de cultivo de 56 dias foi o que mostrou uma proporção mais adequada, em que para cada nove folhas formadas apenas uma estava senescente. Em relação à formação de raízes primárias, médias superiores a 50\% foram observadas após 70 dias de cultivo in vitro, chegando aos melhores resultados (60\%) aos 200 dias. Para raízes secundárias, as maiores médias foram observadas após 102 dias (41,5\%), alcançando 45,3\% aos 200 dias. A micropropagação de Luehea divaricata é afetada significativamente pelo período de cultivo in vitro, que pode ser estendido até aproximadamente 60 dias. A partir desse período, são registradas altas mortalidades.

\section{Effect of different culture periods for Luehea divaricata on micropropagation from shoots}

\begin{abstract}
The objective of the present study was to evaluate the effect of different in vitro culture periods of micropropagated Luehea divaricata shoots. The treatments were constituted by different in vitro culture periods $(14 ; 21 ; 28 ; 40 ; 56 ; 70 ; 84 ; 102 ; 116 ; 130$; 154,186 or 200 days), without subculture or transfer to a new nutritive medium. The survival and establishment reached around $90 \%$ up to 84 days. After that, the mortality increased. Culture period of 56 days was the one that showed the most appropriate proportion of number of leaves and senescent leaves, simultaneously, showing nine leaves and only one senescent. Averages above 50\% were observed for primary roots formation after 70 days of in vitro culture, providing the best results $(60 \%)$ at 200 days. For secondary roots, the highest averages were observed after 102 days (41.5\%), reaching $45.3 \%$ at 200 days. The micropropagation of Luehea divaricata is significantly affected by the in vitro culture period, which can be extended up to approximately 60 days. From that period, high mortality and leaf senescence are registered.
\end{abstract}




\section{Introdução}

Luehea divaricata é uma espécie florestal nativa do Brasil, pertencente à família Malvaceae. Sua madeira é muito empregada na confecção de cadeiras, hélices de avião, estruturas de móveis e caixotaria, o que ocasionou a devastação de suas populações naturais nas últimas décadas (Flôres et al., 2011). Frente a esta diminuição das populações naturais da espécie, a conservação genética de Luehea divaricata é de suma importância para garantir a sua preservação.

A micropropagação surge como uma alternativa tanto para a multiplicação dos genótipos de interesse, quanto para a conservação de recursos genéticos (Flôres et al., 2011; Silva et al., 2019, 2020). Essa técnica da cultura de tecidos permite obter, simultaneamente, progressos no melhoramento de plantas por meio da propagação vegetativa, com uma menor incidência de doenças e independente do clima e da época do ano (Fermino Júnior \& Scherwinski-Pereira, 2012; Oliveira et al., 2013), bem como a conservação de recursos genéticos florestais, pela germinação in vitro de sementes.

A germinação in vitro das sementes possibilita manter a variabilidade genética das populações remanescentes. As sementes são originadas de células que passaram por meiose e apresentam a recombinação entre segmentos cromossômicos, implicando na formação de gametas com diferentes constituições genotípicas, o que garante a diversidade genética (Dutra et al., 2016; Araujo et al., 2018). Com isso, a micropropagação de Luehea divaricata, utilizando propágulos seminais, permite que algumas características fenotípicas sejam herdadas para a geração seguinte, ao mesmo tempo em que a variabilidade genética esteja presente (Araujo et al., 2018).

O sucesso da micropropagação em espécies florestais nativas envolve uma série de fatores, dentre eles estão os componentes nutricionais do meio, fitorreguladores empregados, fatores genéticos, contaminação por microrganismos, oxidação fenólica, senescência foliar e período de cultivo in vitro (Oliveira et al., 2013; Sartor et al., 2013). A senescência foliar, em especial, é um processo degenerativo relacionado ao ciclo de vida das folhas. Pode ser acelerada pela liberação de etileno pelos tecidos vegetais que estão sendo cultivados in vitro e, de modo geral, está associada ao aumento da respiração, perda de clorofila e de coloração (Taiz \& Zeiger, 2004; Barria, 2005).
Poucos estudos relatam o monitoramento da senescência foliar em tecidos cultivados in vitro de espécies florestais nativas do Brasil. Em brotações de Annona glabra L. (ariticum), nas quais foram testadas as citocininas 6-Benzilaminopurina, Thidiazuron, Cinetina e Zeatina na concentração de $1 \mathrm{mg} \mathrm{L}^{-1}$, adicionadas ao meio nutritivo WPM (Wood Plant Medium), após 45 dias de cultivo in vitro, foi observado que esses fitorreguladores foram eficientes no retardo da degradação de clorofilas, reduzindo a senescência foliar (Oliveira et al., 2007).

Os resultados obtidos com esse tipo de estudo podem auxiliar no planejamento da micropropagação, indicando as necessidades de subcultivos, tanto para otimizar a multiplicação como para viabilizar a conservação in vitro de germoplasma. A necessidade de subcultivos pode comprometer o sucesso da micropropagação, sendo extremamente importante determinar o período de cultivo in vitro máximo que a espécie consegue permanecer no mesmo meio nutritivo, visando reduzir e otimizar mão-de-obra, espaço necessário e custos. O período de cultivo in vitro está relacionado ao comportamento e desenvolvimento da espécie nas determinadas condições do ensaio. Algumas espécies podem permanecer meses em um mesmo meio nutritivo sem a adição de fitorreguladores, ao passo que outras conseguem sobreviver apenas algumas semanas (Sá et al., 2012; Xavier et al., 2013).

O objetivo do trabalho foi avaliar o efeito do período de cultivo na micropropagação de brotações de Luehea divaricata.

\section{Material e métodos}

O trabalho foi realizado na Universidade Federal de Santa Maria (Santa Maria, RS), nos laboratórios do Núcleo de Biotecnologia e Melhoramento do Departamento de Fitotecnia. O delineamento experimental utilizado neste ensaio foi o inteiramente casualizado, em arranjo unifatorial, e os tratamentos foram compostos pelos diferentes períodos de cultivo in vitro: $14,21,28,40$, $56,70,84,102,116,130,154,186$ ou 200 dias, sem que ocorresse subcultivo ou transferência para outro meio nutritivo, totalizando 13 tratamentos. Os explantes utilizados no presente ensaio foram segmentos nodais de Luehea divaricata com aproximadamente $10 \mathrm{~mm}$ de comprimento, provenientes do desenvolvimento de 
plântulas obtidas via germinação in vitro, com cultivo em meio nutritivo MS (Murashige \& Skoog, 1962) durante 60 dias (Silva et al., 2019). As unidades experimentais foram compostas por um frasco de $150 \mathrm{~mL}$, contendo $30 \mathrm{~mL}$ de meio nutritivo e dois explantes, totalizando 106 explantes, distribuídos em 53 frascos. O meio nutritivo utilizado foi o MS, e foi acrescentado $30 \mathrm{~g} \mathrm{~L}^{-1}$ de sacarose, $100 \mathrm{mg} \mathrm{L}^{-1}$ de mio-inositol e $7 \mathrm{~g} \mathrm{~L}^{-1} \mathrm{de}$ ágar, e o pH do meio nutritivo foi ajustado para 5,8. Após a preparação do meio nutritivo, os frascos foram autoclavados por 15 min a $121{ }^{\circ} \mathrm{C}$ e $1 \mathrm{~atm}$ de pressão. Os frascos foram vedados com papel alumínio após a inoculação dos explantes, e mantidos em sala de cultivo com temperatura e intensidade luminosa controladas $\left(25^{\circ} \mathrm{C} \pm 3{ }^{\circ} \mathrm{C}\right.$, fotoperíodo de $16 \mathrm{~h}$ e intensidade luminosa de $20 \mu \mathrm{mol} \mathrm{m} \mathrm{m}^{-2} \mathrm{~s}^{-2}$.

Ao final de cada período de cultivo, foram realizadas as avaliações do ensaio. As variáveis consideradas foram: a sobrevivência, verificada pela presença de explantes com coloração verde (\%); o estabelecimento, registrado quando os explantes apresentavam qualquer aspecto de desenvolvimento (\%); a contaminação microbiana, determinada pela presença de micélios fúngicos ou colônias bacterianas junto aos explantes e/ou no meio nutritivo (\%); o número total de folhas; folhas com sinais de senescência, definida pela perda da coloração verde ou presença de folhas com manchas escurecidas (\%); as raízes primárias, que são as raízes adventícias primárias originadas da base do explante (\%) e as raízes secundárias, que são as raízes adventícias laterais de segunda ordem originadas a partir das primárias) (\%).

Nas análises estatísticas empregou-se o pacote estatístico Sisvar (Sistema para Análise de Variância) para Windows ${ }^{\circledR}$ versão 5.1 (Ferreira, 2014). A normalidade dos erros foi testada por meio do teste de Kolmogorov-Smirnov e a homogeneidade de variâncias pelo teste de Bartlett. Quando necessário, as médias foram transformadas pela função $\sqrt{x+0,5}$, sendo $\mathrm{x}$ o valor observado. Na sequência, os dados foram submetidos à análise de variância e, quando o valor de F foi significativo, utilizou-se o teste de Scott-Knott ao nível de 5\% de probabilidade de erro para comparação das médias. A precisão dos ensaios foi estimada pelo índice de variação (Equação 1), conforme indicado por Pimentel-Gomes (2009).

$$
\mathrm{IV}=\frac{\mathrm{CV}}{\sqrt{\mathrm{N}}}
$$

Em que: IV = índice de variação; $\mathrm{CV}=$ coeficiente de variação e $\mathrm{N}=$ número de repetições.

\section{Resultados}

Foi observada diferença significativa entre os períodos avaliados para todas as variáveis avaliadas (Tabela 1): sobrevivência ( $\mathrm{p}=0,0000 ; \mathrm{IV}=1,94)$, estabelecimento $(p=0,0000 ; I V=2,10)$, contaminação microbiana $(\mathrm{p}=0,0136 ; \mathrm{IV}=2,77)$, número total de folhas $(\mathrm{p}=0,0000$; IV $=3,99)$, folhas com sinais de senescência $(p=0,0000$; $\mathrm{IV}=4,49)$, raízes primárias ( $\mathrm{p}=0,0000 ; \mathrm{IV}=2,64)$ e raízes secundárias $(p=0,0000 ; I V=2,73)$. A sobrevivência e o estabelecimento in vitro ficaram em torno de $90 \%$ até os 84 dias de cultivo, sendo que a partir deste período as plantas começaram a registrar mortalidades mais acentuadas (Tabela 1).

Observou-se que, apesar das plantas continuarem a desenvolver um número significativo de folhas $(14,05)$ até cerca de 180 dias de cultivo in vitro sem a troca do meio nutritivo por meio fresco, a senescência nesse período foi muito elevada, indicando que a relação folhas novas e folhas com sinais de senescência não é positiva. O período de cultivo que mostra uma proporção mais adequada parecer ser de 56 dias, no qual para cada nove folhas formadas, apenas uma está senescendo (Tabela 1).

Os sinais de senescência foliar em Luehea divaricata iniciaram aos 40 dias, mas em níveis muito reduzidos, sendo que apenas aos 56 dias foi possível obter média superior a uma folha com sinal de senescência por explante (Tabela 1; Figura 1).

Em relação à formação de raízes primárias, médias superiores a $50 \%$ foram observadas após 70 dias de cultivo in vitro, chegando aos melhores resultados $(60 \%)$ aos 200 dias de cultivo. Em relação às raízes secundárias, as maiores médias foram observadas somente após 102 dias (41,5\%), alcançando aos 200 dias de cultivo in vitro médias de 45,28\% (Tabela 1; Figura 1). 
Tabela 1. Médias de sobrevivência (S), estabelecimento (E), contaminação microbiana (C), número total de folhas (NF), folhas com sinais de senescência (NFS), raízes primárias (RP) e raízes secundárias (RS) na micropropagação de Luehea divaricata (açoita-cavalo) em função dos diferentes períodos de cultivo avaliados.

Table 1. Average of survival (S), establishment (E), contamination (C), number of leaves (NF), leaves with traces of senescence (NFS), primary roots (RP) and secondary roots (RS) in micropropagation of Luehea divaricata depending on the culture period evaluated.

\begin{tabular}{|c|c|c|c|c|c|c|c|}
\hline Período (dias) & $\mathrm{S}(\%)$ & E $(\%)$ & $\mathrm{C}(\%)$ & NF & NFS (\%) & RP (\%) & RS (\%) \\
\hline 14 & $100,00 \mathrm{a}$ & $89,62 \mathrm{a}$ & $3,77 \mathrm{a}$ & $3,10 \mathrm{~d}$ & $0,00 \mathrm{a}$ & $5,60 \mathrm{~d}$ & $0,00 \mathrm{~d}$ \\
\hline 21 & $96,22 \mathrm{a}$ & $90,56 \mathrm{a}$ & $3,77 \mathrm{a}$ & $4,49 \mathrm{~d}$ & $2,44 \mathrm{a}$ & $16,00 \mathrm{~d}$ & $0,00 \mathrm{~d}$ \\
\hline 28 & $96,22 \mathrm{a}$ & $91,50 \mathrm{a}$ & $3,77 \mathrm{a}$ & $5,67 \mathrm{c}$ & $5,82 \mathrm{a}$ & $29,24 \mathrm{c}$ & $1,80 \mathrm{~d}$ \\
\hline 40 & $96,22 \mathrm{a}$ & $92,45 \mathrm{a}$ & $3,77 \mathrm{a}$ & $6,86 \mathrm{c}$ & $10,05 \mathrm{a}$ & $39,62 \mathrm{~b}$ & $8,40 \mathrm{c}$ \\
\hline 56 & $96,22 \mathrm{a}$ & $92,45 \mathrm{a}$ & $5,66 \mathrm{a}$ & $9,30 \mathrm{~b}$ & $15,16 \mathrm{a}$ & $46,22 \mathrm{~b}$ & $16,98 \mathrm{c}$ \\
\hline 70 & $94,33 \mathrm{a}$ & $90,56 \mathrm{a}$ & $7,54 \mathrm{a}$ & $10,49 b$ & $22,78 \mathrm{~b}$ & 54,71 a & $26,41 \mathrm{~b}$ \\
\hline 84 & $90,56 \mathrm{a}$ & 89,62 a & $7,54 \mathrm{a}$ & $11,28 \mathrm{~b}$ & $27,92 \mathrm{~b}$ & $55,66 \mathrm{a}$ & $33,96 \mathrm{~b}$ \\
\hline 102 & $85,84 \mathrm{~b}$ & $84,90 \mathrm{a}$ & $11,32 \mathrm{~b}$ & $11,90 \mathrm{~b}$ & $34,95 \mathrm{c}$ & $57,54 \mathrm{a}$ & $41,50 \mathrm{a}$ \\
\hline 116 & $83,01 \mathrm{~b}$ & $82,07 \mathrm{a}$ & $11,32 \mathrm{~b}$ & $12,37 \mathrm{~b}$ & $37,67 \mathrm{c}$ & 58,49 a & $45,28 \mathrm{a}$ \\
\hline 130 & $80,18 \mathrm{~b}$ & $83,01 \mathrm{a}$ & $15,09 \mathrm{~b}$ & $12,84 \mathrm{a}$ & $44,31 \mathrm{~d}$ & 58,49 a & $44,33 \mathrm{a}$ \\
\hline 154 & $67,92 \mathrm{c}$ & $67,92 \mathrm{~b}$ & $16,98 \mathrm{~b}$ & $14,71 \mathrm{a}$ & $53,97 \mathrm{e}$ & $62,26 \mathrm{a}$ & $47,16 \mathrm{a}$ \\
\hline 186 & $48,11 \mathrm{~d}$ & $48,11 \mathrm{c}$ & $18,86 \mathrm{~b}$ & $14,05 \mathrm{a}$ & $70,60 \mathrm{f}$ & $60,37 \mathrm{a}$ & $44,33 \mathrm{a}$ \\
\hline 200 & $33,96 \mathrm{e}$ & $33,96 \mathrm{~d}$ & $18,86 \mathrm{~b}$ & $14,45 \mathrm{a}$ & $79,10 \mathrm{~g}$ & $60,37 \mathrm{a}$ & $45,28 \mathrm{a}$ \\
\hline Média & 82,21 & 79,74 & 9,86 & 10,11 & 31,13 & 45,35 & 27,34 \\
\hline IV & 1,94 & 2,1 & 2,77 & 3,99 & 4,49 & 2,64 & 2,73 \\
\hline
\end{tabular}

$\mathrm{IV}$ = índice de variação. Médias seguidas da mesma letra minúscula nas colunas, não diferem significativamente pelo teste de Scott-Knott $(\mathrm{p}>0,05)$.
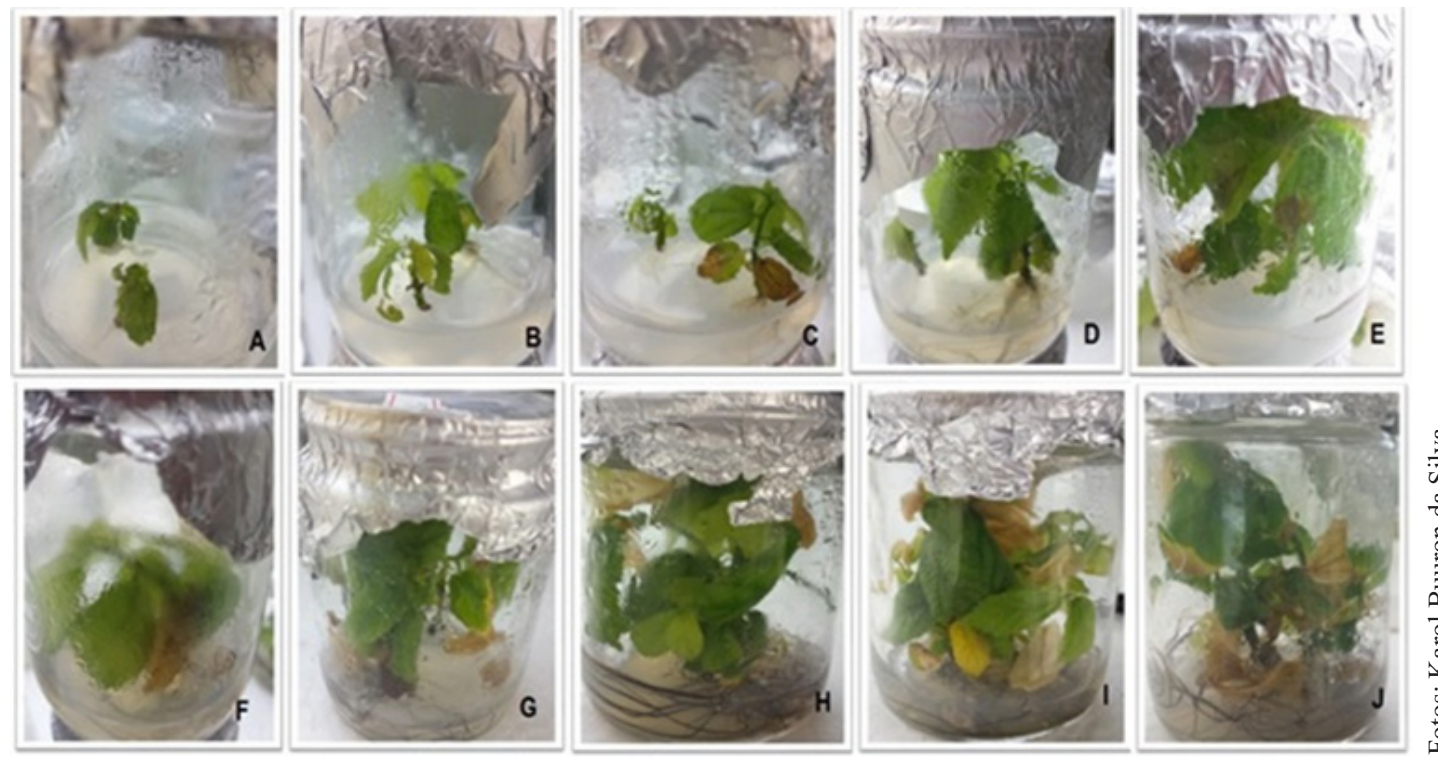

Figura 1. Desenvolvimento das plantas de Luehea divaricata (açoita-cavalo) cultivadas em meio nutritivo MS em função dos períodos de cultivo in vitro: A) 40; B) 56; C) 70; D) 84; E) 102; F) 116; G) 130; H) 154, I) 186 e J) 200 dias.

Figure 1. Development of Luehea divaricata plants growing in MS nutrient medium according to the in vitro culture period: A) 40; B) 56; C) 70; D) 84; E) 102; F) 116; G) 130; H) 154, I) 186 and J) 200 days. 


\section{Discussão}

O período de sobrevivência de 84 dias (Tabela 1) permite que as plantas permaneçam no mesmo meio de cultivo, não sendo necessários subcultivos do material vegetal, o que torna o processo de micropropagação mais econômico e ao mesmo tempo mais seguro, em função da menor probabilidade de perda das culturas pela manipulação (Esposito-Polesi et al., 2015; EspositoPolesi, 2020). Da mesma maneira, a contaminação microbiana até aos 84 dias foi de apenas 7,54\%, sendo que o maior valor $(18,86 \%)$ observado para essa variável ocorreu após 200 dias de cultivo in vitro (Tabela 1). A contaminação por micro-organismos é um problema frequentemente relatado na micropropagação, principalmente por inviabilizar a técnica, caso seja muito elevada (Oliveira et al., 2013; Torres et al., 2016). No entanto, esse não foi um problema enfrentado no cultivo in vitro de Luehea divaricata.

A espécie manteve a capacidade morfogenética dos tecidos, mesmo com as culturas in vitro permanecendo no meio nutritivo original, com a redução da disponibilidade de nutrientes, pois novas folhas se desenvolveram ao mesmo tempo que já havia sinais de senescência, e de abscisão foliar (Tabela 1). Provavelmente, isso ocorreu porque as plantas redirecionaram os nutrientes para as folhas novas, em decorrência de um aumento gradual na síntese de etileno, que, por sua vez, ativa várias enzimas de degradação celular e potencializa a remobilização de estruturas altamente energéticas contidas principalmente nos cloroplastos. Essa liberação de etileno que ocorre pelos tecidos vegetais que são cultivados in vitro está associada ao aumento na respiração, perda de clorofila e de coloração (Taiz \& Zeiger, 2004; Barria, 2005; Barrueto Cid \& Teixeira, 2010).

Considerando-se as dificuldades de enraizamento in vitro das espécies lenhosas, e analisando-se que no presente trabalho não foram adicionados fitorreguladores ao meio nutritivo, a formação in vitro de raízes (Tabela 1, Figura 1) está relacionada à biossíntese de auxinas pelas plantas, haja vista que, muitas vezes, o nível de auxinas endógenas pode ser suficiente para promover a indução de raízes (Pasa et al., 2012; Xavier et al., 2013; Faganello et al., 2015). No entanto, o período para a formação de raízes primárias e secundárias foi de aproximadamente três meses, o que torna o processo de micropropagação lento, com intensificação do processo de senescência a partir dos 70 dias.
A suplementação do meio nutritivo com auxinas face a esse comportamento seria justificada, promovendo a rizogênese de forma mais rápida e eficaz, como foi verificado em trabalho realizado com essa espécie, em que o emprego de $10 \mu \mathrm{M}$ de AIB propiciou médias de formação de raízes primárias e secundárias de cerca de $80 \%$ e $50 \%$, respectivamente, aos 60 dias de cultivo in vitro (dados não publicados). Em plantas de Amburana acreana (cerejeira), os maiores percentuais de enraizamento $(70 \%)$ ocorreram na presença de AIB (Fermino Júnior \& Scherwinski-Pereira, 2012), ratificando que a auxina promove a rizogênese de forma mais rápida, sendo uma alternativa de suplementação no meio nutritivo para acelerar o processo de enraizamento de Luehea divaricata.

\section{Conclusão}

A micropropagação de brotações de Luehea divaricata é afetada significativamente pelo período de cultivo in vitro. Quando consideradas em conjunto as variáveis sobrevivência, estabelecimento, contaminação microbiana, formação de folhas e folhas senescentes, é indicado efetuar o primeiro subcultivo aproximadamente após 60 dias de cultivo in vitro. Decorrido esse período, são registradas altas mortalidades e senescência foliar, comprometendo a micropropagação.

\section{Agradecimentos}

O presente trabalho foi realizado com o apoio da Coordenação de Aperfeiçoamento de Pessoal de Nível Superior (CAPES - 88882.427782/2019-01) e pelo Conselho Nacional de Desenvolvimento Científico e Tecnológico (CNPq - 312499/2018-3).

\section{Referências}

Araujo, M. M. et al. Produção de sementes e mudas: um enfoque à silvicultura. Santa Maria, RS: Ed. UFSM, 2018. 448 p.

Barria, M. J. Etileno em plantas superiores: síntese e propriedades fisiológicas. In: Barrueto Cid, L. P. Hormônios vegetais em plantas superiores. Brasília, DF: Embrapa Recursos Genéticos e Biotecnologia, 2005. v. 01. p. 102-125.

Barrueto Cid, L. P. \& Teixeira, J. B. Oxidação fenólica,vitrificação e variação somaclonal. In: Barrueto Cid, L. P. Cultivo in vitro de plantas. Brasília, DF: Embrapa Recursos Genéticos e Biotecnologia, 2010. v. 1, p. 51-66. 
Dutra, A. F. et al. Germinação de sementes e emergência de plântulas de Luehea divaricata Mart. et. Zucc. em diferentes substratos. Ciência Florestal, v. 26, n. 2, p. 411-418, 2016. https://doi. org/10.5902/1980509822744.

Esposito-Polesi, N. P. et al. Endophytic bacterial communities associated with two explant sources of Eucalyptus benthamii Maiden \& Cambage. World Journal of Microbiology and Biotechnology, v. 31, p. 1737-1746, 2015. http://dx.doi.org/10.1007/s11274-0151924-0.

Esposito-Polesi, N. P. Contaminação versus manifestação endofítica: implicações no cultivo in vitro de plantas. Rodriguésia, v. 71, p. 115, 2020. http://dx.doi.org/10.1590/2175-7860202071072.

Faganello, L. R. et al. Efeito dos ácidos indolbutírico e naftalenoacético no enraizamento de estacas semilenhosas de Cordia trichotoma (Vell.) Arrab. ex Steud. Ciência Florestal, v. 25, n. 4, p. 863-871, 2015. https://doi.org/10.5902/1980509820584.

Fermino Junior, P. C. P. \& Scherwinski-Pereira J. E. Germinação e propagação in vitro de cerejeira (Amburana acreana (Ducke) A.C. Smith - Fabaceae). Ciência Florestal, v. 22, n 1, p. 1-9, 2012. https:// doi.org/10.5902/198050985074.

Ferreira, D. F. Sisvar: a Guide for its Bootstrap procedures in multiple comparisons. Ciência e Agrotecnologia, v. 38, n. 2, p 109-112, 2014. https://doi.org/10.1590/S1413-70542014000200001.

Flôres, A.V. et al. Estabelecimento e multiplicação in vitro de Luehea divaricata Mart. \& Zucc. Ciência Florestal, v. 21, n. 1, p. 175-182, 2011. https://doi.org/10.5902/198050982760.

Murashige, T. \& Skoog, F. K. A revised medium for rapid growth and bio assays with tobacco tissue cultures. Physiologia Plantarum, v. 15, p. 473-497, 1962.

Oliveira, L. M. et al. Efeito de citocininas na senescência e abscisão foliar durante o cultivo in vitro de Annona glabra L. Revista Brasileira de Fruticultura, v. 29, n. 1, p. 25-30, 2007. https://doi. org/10.1590/S0100-29452007000100008.
Oliveira, L. S. et al. Micropropagação de espécies florestais brasileiras. Pesquisa Florestal Brasileira, v. 33, n. 76, p. 445-460, 2013. https://doi.org/10.4336/2013.pfb.33.76.481.

Pasa, M. S. et al. Qualidade de luz e fitorreguladores na multiplicação e enraizamento in vitro da amoreira-preta 'Xavante'. Ciência Rural, v. 42, n. 8, p. 1392-1396, 2012. https://doi.org/10.1590/S010384782012000800010 .

Pimentel-Gomes, F. Curso de estatística experimental. 15. ed. Piracicaba: Livraria Nobel, 2009. 451 p.

Sá, A. J. et al. Sealing and explant types on the mangaba micropropagation. Ciência Agrotécnica, v. 36, n. 4, p. 406-414, 2012. https://doi.org/10.1590/S1413-70542012000400004.

Sartor, F. R. et al. Diferentes meios de cultura e antioxidantes no estabelecimento in vitro do jacarandá da Bahia. Bioscience Journal, v. 29, n. 2, p. 408-411, 2013.

Silva, K. B et al. Rizogênese in vitro em brotações de Luehea divaricata Mart. \& Zucc. Ciência Florestal, v. 29, n. 3, p. 1282-1295, 2019. https://doi.org/10.5902/1980509826045.

Silva, K. B. et al. Sucrose and substrates on the acclimatization of micropropagated Luehea divaricata plants. Floresta e Ambiente, v. 27, n. 1, p. 1-9, 2020. https://doi.org/10.1590/2179-8087.117017.

Taiz, L. \& Zeiger, E. Fisiologia vegetal. Porto Alegre: Artmed, 2004. 719 p.

Torres, G. R. C. et al. Control of contaminants during introduction and establishment of Bambusa vulgaris in vitro. Research in Biotechnology, v 7, p 58-67, 2016. https://doi.org/10.19071/rib.2016. v7.3056.

Xavier, A. et al. Silvicultura clonal: princípios e técnicas. Viçosa, MG: Universidade Federal de Viçosa, 2013. 279 p. 